\title{
Analysis and design of dual-half bridge converter operating in discontinuous conduction mode
}

\author{
Lei Zhao ${ }^{1}$, Tongxin Chen ${ }^{1}$, Chuliang Wei ${ }^{1, \text { a) }}$, and Geng Tang ${ }^{1}$
}

\begin{abstract}
Dual-half bridge (DHB) converter is a novel family of phaseshifted full-bridge (PSFB) converter, and it can obtain a significant improvement in conversion efficiency compared to the traditional PSFB converter. However, the main drawback of DHB converter is that only the energy stored in leakage inductor can be used to discharge the junction capacitors of switches. All switches tend to lose zero-voltage switching (ZVS) under light load conditions, which will significantly degrade efficiency. This paper proposes a simple and effective method to extend the ZVS range of DHB converter. By making the DHB converter operating in discontinuous conduction mode (DCM) and widening the dead-time, the energy stored in the magnetizing inductors of transformers can be used to discharge the junction capacitors. Without additional auxiliary components, the ZVS operation under light load conditions can be obtained. Experimental results confirm the validity of proposed method.

Keywords: full-bridge converter, dual-half bridge converter, zero-voltage switching, discontinuous current mode, light load conditions

Classification: Power devices and circuits
\end{abstract}

\section{Introduction}

In the traditional phase-shifted full-bridge (PSFB) converter, all the primary switches can achieve zero voltage switching (ZVS) operation by using the parasitic components. Hence, the circuit structure is very simple and high switching frequency can be employed without causing large switching loss, which is beneficial for the improvement of reliability and power density $[1,2,3,4,5,6]$. The PSFB converter is widely adopted for isolated applications, such as renewable power system, server power supply unit and battery charger. However, the PSFB converter has several serious drawbacks. First, the ZVS range of lagging-leg switches is very narrow and the switching loss will increase greatly under light load conditions. Then, the rectified diodes suffer from high voltage stress due to the resonance between leakage inductor of main transformer and junction capacitors of diodes [7]. In addition, the voltage across main transformer is maintained at zero while the primary current is nonzero during the freewheeling interval, which results in the increase of output filter requirement and conduction loss.

In order to overcome the aforementioned drawbacks in the traditional PSFB converter, many novel converters have been proposed. In $[8,9,10,11,12,13]$, some auxiliary circuits are

${ }^{1}$ Department of Electronic Engineering, Shantou University, Guangdong, PR China

a) clwei@stu.edu.cn

DOI: $10.1587 /$ elex.17.20200267

Received August 4, 2020

Accepted August 13, 2020

Publicized August 27, 2020

Copyedited September 10, 2020 introduced into the PSFB converter. The junction capacitor of primary switch is discharged by these auxiliary circuits instead of the leakage inductor of main transformer. The auxiliary circuits are considered as constant current source during the ZVS transition, thus, the junction capacitors can be discharged completely over the full-load range. However, the auxiliary circuits increase the volume, cost and complexity of PSFB converter. Moreover, the trade-off between the additional power loss caused by the auxiliary circuits and the power loss saved by the ZVS operation should be resolved.

The simplest way to suppress the secondary voltage oscillation is the use of resistor-capacitor-diode (RCD) clamp circuit [14]. The RCD circuit shows a good performance by limiting the peak value of voltage oscillation. However, it cannot prevent the oscillation itself and the power loss caused by resistor degrades the conversion efficiency. In $[15,16,17,18,19]$, the lossless snubber circuits are implemented to eliminate the voltage oscillation. Power loss of the auxiliary circuit is avoided. In [20, 21], two clamp diodes and a separate inductor are introduced into the primary side of PSFB converter. The peak value of secondary voltage is effectively suppressed by the clamp diodes. But these converters do not deal with the issues of primary circulating current and narrow ZVS range.

In [22, 23, 24, 25], some zero-voltage and zero-current switching (ZVZCS) PSFB converters are proposed to remove circulating current and to extend ZVS range. In these converters, an auxiliary voltage source is introduced into the secondary side or primary side of the traditional converters, which makes the primary current decay to zero during the freewheeling interval. In these ZVZCS converters, the output filter inductor takes part in the ZVS transition of leading-leg and the primary current is maintained at zero when the lagging-leg switches are turned-off. Therefore, the ZVS condition is improved and the primary circulating current is removed. However, during the freewheeling interval, the output power is kept constant by the energy stored in the output filter, which results in high filter requirement.

Recently, some dual-half bridge (DHB) converters are proposed $[26,27,28,29,30]$. In the primary side of DHB converters, two half-bridge inverters are placed in parallel and are driven in a traditional PS manner. In the secondary side, various rectified structures, such as current doubler rectifier [26, 27], center-tap rectifier (CTR) [28], full-bridge rectifier (FBR) [29] and hybrid rectifier [30], can be adopted to suit for different applications. The DHB converters have the following advantages: (1) the circulating current is removed and the conduction loss can be significantly reduced; 
(2) the primary energy is continuously transferred to the output side and the output filter requirement is reduced. Experimental results have shown that the DHB converters can achieve a significant improvement in conversion efficiency compared to the conventional PSFB converter. The main drawback of DHB converters is that only the energy stored in the leakage inductors can be available to discharge the junction capacitors. Since the available energy is dependent on the load current, all the primary switches tend to lose ZVS operation under light load conditions. In order to further extend the ZVS range of DHB converters, this paper proposes a simple and effective method. By making the DHB converter operating in discontinuous conduction mode (DCM) and widening the dead-time of leading-leg and lagging-leg, the magnetizing inductors can participate in ZVS transitions under light load conditions. Since the energies stored in magnetizing inductors are sufficiently larger than the required ZVS energies, all the primary switches can achieve ZVS operation. The proposed method does not use additional components and it is very simple and costeffective.

To introduce the proposed method in detail, the DHB converter with FBR is selected in this paper. In Sections 2, the basic operational principle is presented. The performance analysis is given in Section 3. In Section 4, the experimental results on a $1-\mathrm{kW}$ prototype are reported to verify the theory analysis. Finally, some conclusions are given in Section 5.

\section{Operational principle}

Fig. 1 shows the equivalent circuit of DHB converter with FBR. In the primary side, $Q_{1}-Q_{3}-T_{1}-C_{B}$ and $Q_{2}-Q_{4}-T_{2}-C_{B}$ compose the leading and lagging half-bridge inverters, respectively. Two FBRs sharing two low voltage rating diodes are employed in the secondary side. In order to simplify the theory analysis, the following assumptions are made: (1) the switches are MOSFETs and only parasitic diodes and junction capacitors are considered; (2) the transformers $\mathrm{T}_{1}$ and $\mathrm{T}_{2}$ have the same specifications; the leakage inductances and magnetizing inductances are $L_{k}$ and $L_{m}$, respectively; (3) the output filter capacitor $C_{o}$ and blocking capacitor $C_{B}$ are considered as constant voltage sources of $V_{o}$ and $0.5 V_{i n}$, respectively.

As load current is decreased, the current through output filter inductor will be discontinuous. Fig. 2 shows the key waveforms in DCM operation. $V_{i n}$ is input voltage, $T_{s}$ is switching period. $I_{m}$ and $I_{\max }$ are the maximum currents of magnetizing inductors and output inductor, respectively. The turns ratios $n_{p}: n_{s}$ of $\mathrm{T}_{1}$ and $\mathrm{T}_{2}$ are $1: n$. The dutycycle of rectified voltage is $D$. The phase-shifted modulation is adopted and the phase-shifted time is $0.5 D T_{s}$. All the

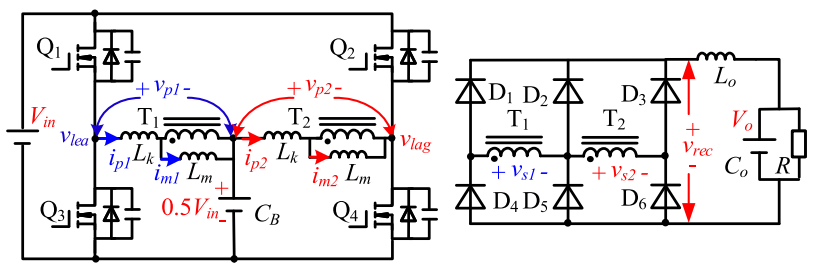

Fig. 1 Simplified equivalent circuit of DHB converter with FBR. primary switches operate with a constant duty-cycle $50 \%$ if dead-time is ignored. Each switching period is divided into two half cycles, $t_{0} \sim t_{7}$ and $t_{7} \sim t_{14}$. Due to the symmetry of circuit, only the first half cycle is introduced. This half cycle is divided into seven modes and the corresponding equivalent circuits are shown in Fig. 3.

Mode $1\left[t_{0} \sim t_{1}\right]$ : This mode is defined as duty-cycle interval. $\mathrm{Q}_{1}, \mathrm{Q}_{4}$ and $\mathrm{D}_{1}, \mathrm{D}_{6}$ are in on-state. The primary voltages of $\mathrm{T}_{1}$ and $\mathrm{T}_{2}$ are $0.5 V_{\text {in }}$. Thus, the magnetizing currents $i_{m 1}(t)$ and $i_{m 2}(t)$ increase linearly, respectively. The rectified voltage $v_{\text {rec }}(t)$ is equal to the sum of the secondary voltages of $\mathrm{T}_{1}$ and $\mathrm{T}_{2}$ and its value is $n V_{i n}$. The current of output filter inductor $i_{L o}(t)$ increase linearly from zero and it is calculated as follow:

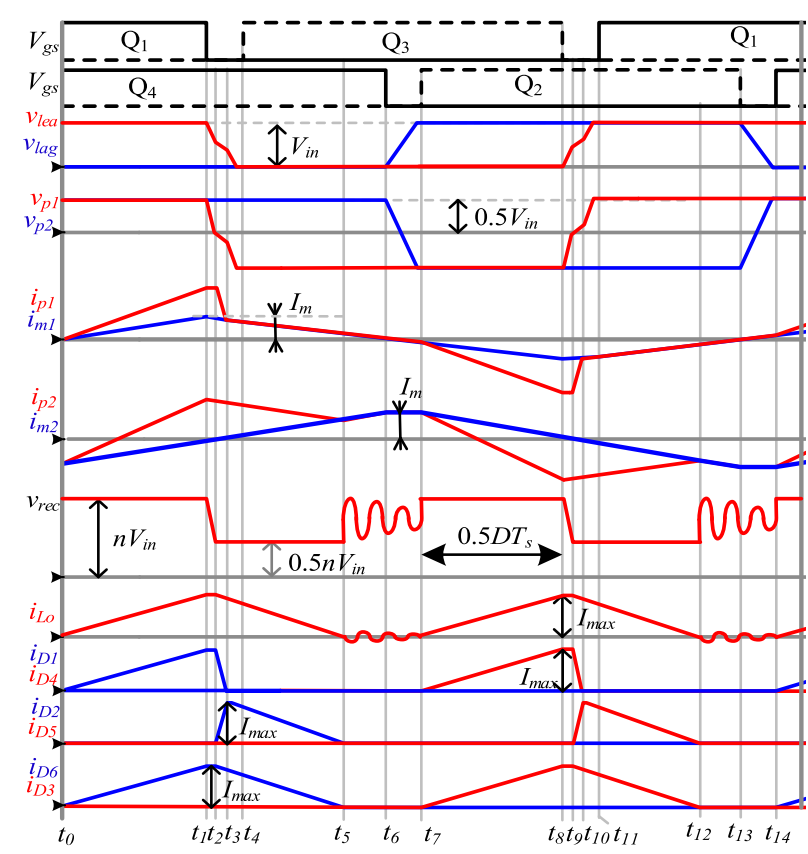

Fig. 2 Key waveforms of DHB converter in DCM.

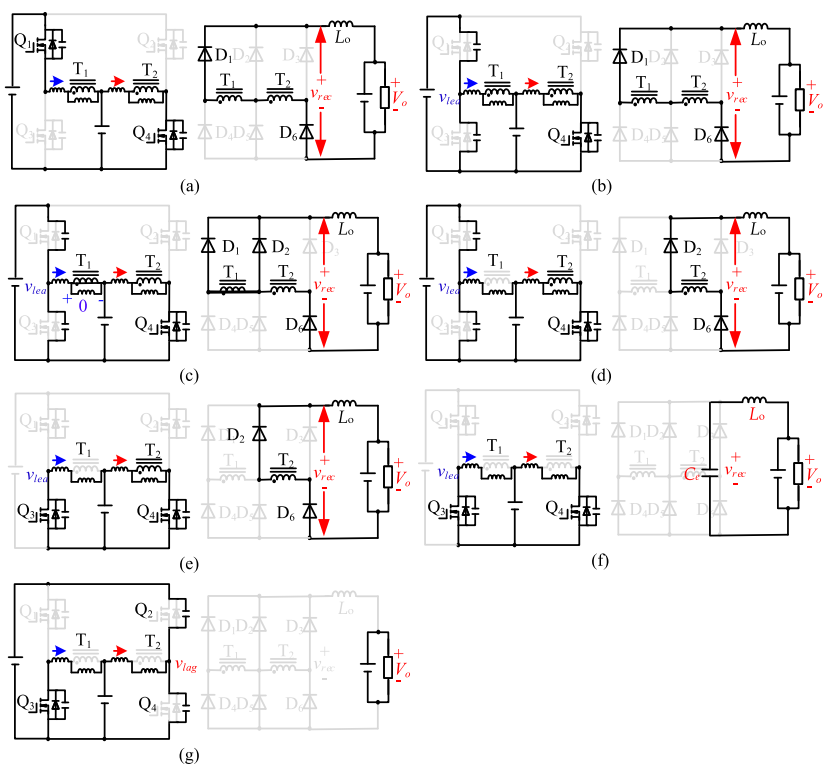

Fig. 3 Equivalent circuits: (a) Mode $1\left[t_{0} \sim t_{1}\right]$; (b) Mode $2\left[t_{1} \sim t_{2}\right]$; (c) Mode $3\left[t_{2} \sim t_{3}\right]$; (d) Mode $4\left[t_{3} \sim t_{4}\right]$; (e) Mode 5 [ $\left.t_{4} \sim t_{5}\right]$; (f) Mode 6 $\left[t_{5} \sim t_{6}\right] ;(\mathrm{g})$ Mode $7\left[t_{6} \sim t_{7}\right]$. 


$$
i_{L o}(t)=\frac{n V_{i n}-V_{o}}{L_{o}}\left(t-t_{0}\right)
$$

Mode $2\left[t_{1} \sim t_{2}\right]: \mathrm{Q}_{1}$ is turned off at $t_{1}$. The duration of this mode is very narrow and all the currents remain constant. The capacitances are discharged linearly by a constant current source $i_{p 1}\left(t_{1}\right) . i_{p 1}\left(t_{1}\right)$ is equal to $I_{m}+n I_{\max }$. The leading-leg voltage $v_{\text {lea }}(t)$, the secondary voltage of $\mathrm{T}_{1}$ $v_{s 1}(t)$, and the rectified voltage $v_{\text {rec }}(t)$ decrease from $V_{i n}$, $0.5 n V_{i n}, n V_{i n}$ to $0.5 V_{i n}, 0$ and $0.5 n V_{i n}$, respectively. At $t_{2}$, $v_{s 1}(t)$ falls to zero and diode $\mathrm{D}_{2}$ starts to conduct.

Mode $3\left[t_{2} \sim t_{3}\right]$ : During this mode, $v_{s 1}(t)$ maintains at zero since $\mathrm{D}_{1}$ and $\mathrm{D}_{2}$ are simultaneously in conducting state. The resonance of junction capacitances and leakage inductance occurs in the primary side. The leading-leg voltage $v_{\text {lea }}(t)$ and current $i_{p 1}(t)$ decrease with sinusoidal shape, and they are calculated as follows:

$$
\begin{gathered}
v_{\text {lea }}(t)=0.5 V_{\text {in }}-\left(n I_{\max }+I_{m}\right) z \sin \omega\left(t-t_{2}\right) \\
i_{p 1}(t)=\left(n I_{\max }+I_{m}\right) \cos \omega\left(t-t_{2}\right)
\end{gathered}
$$

where $\omega=1 / \sqrt{2 C_{\text {oss }} L_{k}}, z=\sqrt{L_{k} / 2 C_{\text {oss }}}$.

The commutation between $\mathrm{D}_{1}$ and $\mathrm{D}_{2}$ is progressed, and $\mathrm{D}_{1}$ current decreases from $I_{\max }$ to zero while $\mathrm{D}_{2}$ current increases from zero to $I_{\max }$. Mode 3 ends when $\mathrm{D}_{1}$ current reaches zero at $t_{3}$.

Mode $4\left[t_{3} \sim t_{4}\right]$ : Mode 4 begins when the commutation between $D_{1}$ and $D_{2}$ is completed and $D_{1}$ is naturally turnedoff. During this mode, the secondary current of $T_{1}$ is zero and the capacitances of leading-leg switches are discharged by the magnetizing current $I_{m}$. The leading-leg voltage $v_{\text {lea }}(t)$ decrease linearly from $0.5 V_{\text {in }}$ to zero. Then, the parasitic diode of $\mathrm{Q}_{3}$ starts to conduct and $\mathrm{Q}_{3}$ can be turned on with ZVS.

In summary, the ZVS transition of leading-leg is constituted of three modes (Mode 2, Mode 3 and Mode 4). During this interval, the leading-leg voltage $v_{\text {lea }}(t)$ and the rectified voltage $v_{\text {rec }}(t)$ decrease from $V_{\text {in }}$ and $n V_{\text {in }}$ to 0 and $0.5 n V_{i n}$, respectively. On the other hand, the voltages and currents of lagging-leg are considered as constant since the duration is very narrow.

Mode $5\left[t_{4} \sim t_{5}\right]$ : During this mode, the secondary current of $\mathrm{T}_{1}$ is zero and the primary power is transferred to the secondary side through only $\mathrm{T}_{2}$. This mode is called as freewheeling interval. The current of output filter inductor decreases from $I_{\max }$ to zero.

$$
i_{L o}(t)=I_{\max }-\frac{V_{o}-0.5 n V_{i n}}{L_{o}}\left(t-t_{4}\right)
$$

Mode $6\left[t_{5} \sim t_{6}\right]$ : Mode 6 begins when $i_{L o}(t)$ falls to zero at $t_{5}$. Then, all rectified diodes are naturally turned off. The secondary currents of $\mathrm{T}_{1}$ and $\mathrm{T}_{2}$ are zero and only the energy stored in the filter capacitor $C_{o}$ is transferred to the output side. This mode is defined as idle interval.

The junction capacitors of rectified diodes are ignored to simplify the analysis. In fact, the resonance of junction capacitors and output filter inductor occurs in the secondary side during this mode. The resonance voltage is calculated as

$$
v_{r e c}(t)=V_{o}-\left(V_{o}-0.5 n V_{i n}\right) \cos \omega_{s} t
$$

where $\omega_{s}=1 / \sqrt{2 C_{e} L_{o}}, C_{e}$ is the equivalent capacitance of rectified diodes.
Mode $7\left[t_{6} \sim t_{7}\right]$ : Mode 7 begins when $\mathrm{Q}_{4}$ is turned off at $t_{6}$. The secondary currents are continuously maintained at zero. The junction capacitors of $\mathrm{Q}_{2}$ and $\mathrm{Q}_{4}$ are charged by the magnetizing current of $\mathrm{T}_{2}$. The lagging-leg voltage $v_{\text {lag }}(t)$ increases linearly. At $t_{7}, v_{\text {lag }}(t)$ increases to $V_{\text {in }}$ and the parasitic diode of $\mathrm{Q}_{2}$ starts to conduct. Then, $\mathrm{Q}_{2}$ can be turned on with zero voltage. At the end of this mode, $\mathrm{D}_{3}$ and $\mathrm{D}_{4}$ start to conduct and the secondary currents increase linearly from zero. The primary power is transferred to the output side through $\mathrm{T}_{1}$ and $\mathrm{T}_{2}$.

\section{ZVS conditions}

As described in the previous section, the ZVS transition of leading-leg switches is constituted of three modes (Mode 2, Mode 3 and Mode 4) when the DHB converter operates in DCM. During Mode 2, the output filter inductor is reflected into the primary side and the leading-leg voltage decreases linearly from $V_{\text {in }}$ to $0.5 V_{\text {in }}$. During Mode 3, the secondary winding of $T_{1}$ is shorted and the junction capacitors of switches are discharged by the energy stored in the leakage inductor of $\mathrm{T}_{1}$. During Mode 4 , the secondary current of $\mathrm{T}_{1}$ is maintained at zero and the junction capacitors are discharged by the magnetizing current. At the end of Mode 4, the leading-leg voltage falls to zero and the ZVS operation can be achieved.

According to the relevant analysis results in [25], the ZVS transition of leading-leg is constituted of two modes in continuous conduction mode (CCM). At first, the leading-leg voltage decreases linearly from $V_{i n}$ to $0.5 V_{\text {in }}$ due to the existence of output filter inductor. Then, the remaining voltage across the junction capacitors is discharged by the leakage inductor of transformer. In the view of energy, the ZVS condition of leading-leg switches is represented as

$$
\frac{1}{2} L_{k}\left(n I_{o}\right)^{2}>\frac{4}{3} C_{o s s}\left(0.5 V_{i n}\right)^{2}
$$

When the DHB converter operates in DCM, the secondary currents of transformers are maintained at zero and the junction capacitors are mainly charged by the magnetizing inductor during the ZVS transition of lagging-leg. The lagging-leg voltage increases linearly from 0 to $V_{i n}$. On the other hand, if the DHB operates in CCM, the current of output inductor is nonzero and rectified didoes keep conducting during the ZVS transition. The secondary windings of transformers are shorted by the rectified diodes. Therefore, only the energy stored in the leakage inductors can be used to charge junction capacitors. The ZVS condition of lagging-leg switches in CCM is represented as

$$
L_{k}\left(n I_{o}+I_{m}\right)^{2}>\frac{4}{3} C_{o s s} V_{i n}^{2}
$$

From (6) and (7), it can be noted that the available energy charging or discharging the junction capacitors is dependent on the energy stored in leakage inductors, which is directly decided by the load current. Therefore, all the primary switches tend to lose ZVS operation under light load conditions if the DHB converter operates in CCM. This is in contrast to the fact that the available energy is mainly stored in the magnetizing inductors if the DHB converter 
operates in DCM. Since the magnetizing inductance is large enough, the available energy is also sufficiently larger than the required ZVS energy.

The peak value of magnetizing current is calculated as follow:

$$
I_{m}=\frac{V_{i n} T_{s}}{8 L_{m}}
$$

$I_{m}$ is independent on load current. Based on the aforementioned analysis, the junction capacitors of switches are mainly discharged or charged by the magnetizing current $I_{m}$ when the DHB converter operates in DCM. Therefore, the ZVS conditions of lagging-leg switches and leading-leg switches are also independent on the load conditions and a full ZVS range can be achieved. It should be noted that the value of magnetizing current is usually very small and the dead-time are widened to ensure that capacitors are charged or discharged completely by the magnetizing current [31].

\section{Design example and experimental results}

In order to verify the theory analysis of DHB converter operating in DCM, an experimental prototype converter is built with the following specifications: input voltage $V_{\text {in }}=$ $320 \sim 400 \mathrm{~V}$; output voltage $V_{o}=100 \mathrm{~V}$; switching frequency $f_{s}=50 \mathrm{kHz} ;$ maximum load current $I_{o}=10 \mathrm{~A}$.

Main transformers: Based on the window-area product of magnetic core required for the maximum power capacity, PQ3535 is selected as the core of transformers. When input voltage is the minimum and the corresponding maximum duty-cycle is preset 0.9 , the turns ratio can be calculated according to the voltage gain of DHB converter in CCM, and its value is 0.34 .

Magnetizing inductor: The specified value of magnetizing inductor is designed by adjusting the gap of magnetic core. A wide ZVS range can be achieved by reducing the magnetizing inductance and increasing the magnetizing current. In spite of using a small magnetizing inductance, the primary current stress will not increase significantly because the average value of magnetizing current is zero within a half period and its contribution to the total RMS current can be ignored. In this paper, the maximum magnetizing current is selected as $0.5 \mathrm{~A}$. The magnetizing inductance is determined from (8) and its value is $1.5 \mathrm{mH}$.

Output filter inductor: The output filter inductor is designed based on the waveform of rectified voltage and its value is calculated as follows

$$
L_{o}=\frac{V_{o}}{4 f_{s} \Delta I_{o}} \frac{D(1-D)}{1+D}
$$

where $\Delta I_{o}$ is the current ripple of output filter inductor.

The current ripple has a significant effect on the performance of DHB converter since it decides the critical point between CCM and DCM. According to the ZVS conditions of DHB converter, the ZVS range can be extended by increasing $\Delta I_{o}$, which results in high current stress. A tradeoff should be made in the design process. Generally, $\Delta I_{o}$ is set around $30 \%$ of maximum load current. In this paper, $\Delta I_{o}$ is selected as $3 \mathrm{~A}$. Then, the value of output filter inductor can be calculated based on (9), and it is $25 \mu \mathrm{H}$.

The voltage and current stresses of rectified diodes and

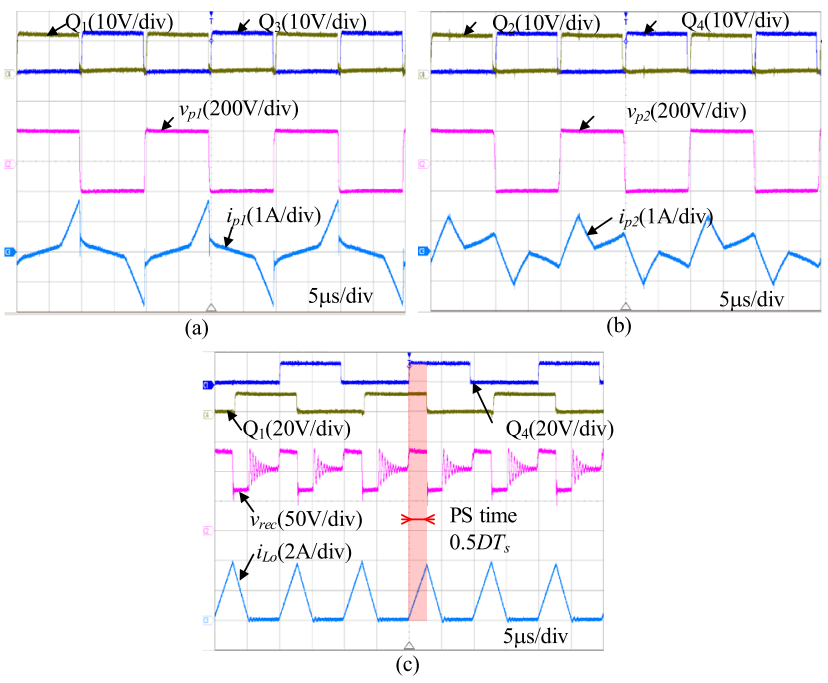

Fig. 4 Experimental waveforms of DHB converter in DCM. (a) Leadingleg; (b) lagging-leg; (c) secondary side.

primary switches can be obtained by calculating the maximum values as follows:

$$
\begin{gathered}
I_{D 1-6(\max )}=I_{o(\max )}+\Delta I_{o}=13 \mathrm{~A} \\
V_{D 1,3,4,6(\max )}=n V_{i n}=136 \mathrm{~V} \\
V_{D 2,5(\max )}=0.5 n V_{i n}=68 \mathrm{~V} \\
V_{Q 1-4(\max )}=V_{i n(\max )}=400 \mathrm{~V} \\
I_{Q 1-4(\max )}=n\left(I_{o(\max )}+\Delta I_{o}\right)+I_{m}=4.9 \mathrm{~A}
\end{gathered}
$$

Based on the aforementioned values, $\mathrm{D}_{1}, \mathrm{D}_{3}, \mathrm{D}_{4}, \mathrm{D}_{6}$ are selected as MBR20200CT (200 V, 20 A) and $\mathrm{D}_{2}, \mathrm{D}_{5}$ are selected as MBR20150CT $(150 \mathrm{~V}, 20 \mathrm{~A})$. The primary switches are selected as STW10NK60Z (600 V, $10 \mathrm{~A})$.

Fig. 4 shows the key experimental waveforms of DHB converter operating in DCM. The leading current $i_{p 1}$ increases linearly during the duty-cycle interval and it falls quickly from the maximum value to the magnetizing current during the ZVS transition. The lagging current $i_{p 2}$ contains three slopes during one half cycle. As shown in Fig. 4(c), during the duty-cycle interval, the rectified voltage $v_{\text {rec }}$ is $n V_{i n}$ and the current of filter inductor $i_{L o}$ increases linearly. During the freewheeling interval, $v_{r e c}$ is $0.5 n V_{i n}$ and $i_{L o}$ decreases linearly. When $i_{L o}$ falls to zero, the resonance between junction capacitors of rectified diodes and output filter inductor occurs in the secondary power path. The experimental results coincide well with the theory waveforms described in Fig. 2.

Fig. 5 and Fig. 6 show the ZVS waveforms of leadingleg and lagging-leg switches under light load conditions, respectively. As shown in Fig. 5 and Fig. 6, although the reflected current of output filter inductor falls to zero during the ZVS transitions, all the switches can still achieve ZVS operation by using the magnetizing current to discharge the junction capacitors.

\section{Conclusion}

This paper proposes a practical and simple way to extend the ZVS range of DHB converter. By making the DHB converter operating in DCM and widening the dead time of leading-leg 


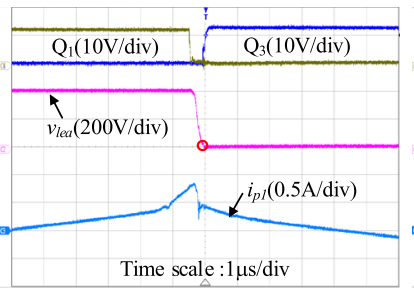

(a)

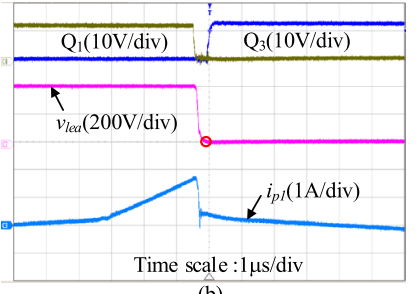

(b)

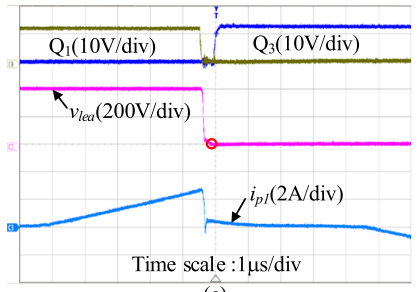

(c)

Fig. 5 ZVS waveforms of leading switches under light load conditions (a) $1 \%$ of full load; (b) $10 \%$ of full load; (c) $30 \%$ of full load.

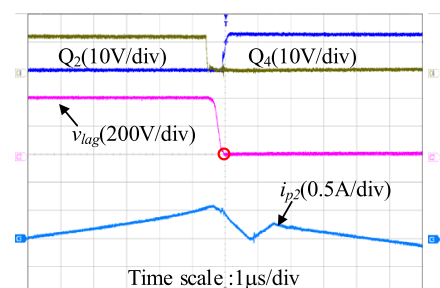

(a)

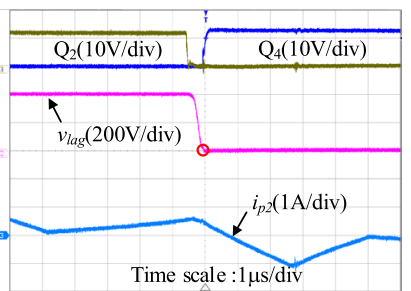

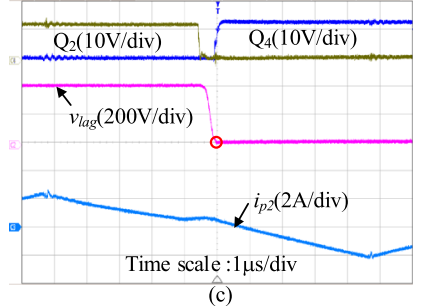

Fig. 6 ZVS waveforms of lagging switches under light load conditions. (a) $1 \%$ of full load; (b) $10 \%$ of full load; (c) $30 \%$ of full load.

and lagging-leg, the magnetizing inductors can be used to participate in the ZVS transitions. Since the energy stored in the magnetizing inductor is sufficiently larger than the required ZVS energy and they are independent on the load conditions, the ZVS operation can be achieved under light load conditions without additional components. The validity of proposed method is confirmed by the experimental results.

\section{Acknowledgments}

This research was funded by the Characteristic Innovation Project of Universities in Guangdong Province, grant number 2018KTSCX061, and by the Foundation for Distinguished Young Talents in Higher Education of Guangdong, grant number 2018KQNCX080, and by the National Natural Science Foundation of Guangdong, grant number 2019A1515011060, and by the National Natural Science Foundation of China, grant number 51907113.

\section{References}

[1] C.-M. Lin and M.-C.Li: "Buck-current-fed zero current switching converter for high voltage coupled cavity," IEICE Electron. Express
9 (2012) 1362 (DOI: 10.1587/elex.9.1362).

[2] K. Itoh, et al.: " $28 \mathrm{~W} / \mathrm{cm}^{3}$ high power density three-port DC/DC converter cell for dual-voltage 12-V/48-V HEV subsystem," IEICE Electron. Express 14 (2017) 20170781 (DOI: 10.1587/elex.14.20170781).

[3] X. Zhang, et al.: "Optimal mileage based AGC dispatch of a GenCo," IEEE Trans. Power Syst. 35 (2020) 2516 (DOI: 10.1109/TPWRS. 2020.2966509).

[4] U. Badstuebner, et al.: "Optimization of a 5-kW telecom phaseshift DC-DC converter with magnetically integrated current doubler," IEEE Trans. Ind. Electron. 58 (2011) 4736 (DOI: 10.1109/ TIE.2010.2103536).

[5] X. Zhang, et al.: "Dynamic surrogate model based optimization for MPPT of centralized thermoelectric generation system under heterogeneous temperature differences," IEEE Trans. Energy Convers. 35 (2020) 966 (DOI: 10.1109/TEC.2020.2967511).

[6] G. Ranipriya, et al.: "An integrated four port bidirectional dc-dc converter for photovoltaic energy harvesting systems," IEICE Electron. Express 16 (2019) 20190495 (DOI: 10.1587/elex.16.20190495).

[7] Z. Chen, et al.: "Mechanism and suppression countermeasure of voltage oscillation for full bridge converter," IET Power Electron. 5 (2011) 1535 (DOI: 10.1049/iet-pel.2011.0502).

[8] V.R.K. Kanamarlapudi, et al.: "A new ZVS full-bridge DC-DC converter for battery charging with reduced losses over full-load range," IEEE Trans. Ind. Appl. 54 (2018) 571 (DOI: 10.1109/TIA. 2017.2756031).

[9] Y. Jang and M.M. Jovanovic: "A new family of full-bridge ZVS converters," IEEE Trans. Power Electron. 19 (2004) 701 (DOI: 10.1109/ TPEL.2004.826493).

[10] A. Safaee, et al:: "A ZVS pulsewidth modulation full-bridge converter with a low-RMS-current resonant auxiliary circuit," IEEE Trans. Power Electron. 31 (2016) 4031 (DOI: 10.1109/TPEL.2015. 2473822).

[11] M. Borage, et al.: "A full-bridge DC-DC converter with zero-voltageswitching over the entire conversion range," IEEE Trans. Power Electron. 23 (2008) 1743 (DOI: 10.1109/TPEL.2008.925203).

[12] S.-Z. Chen, et al.: "Immunizing variable frequency transformer from dual-side asymmetrical grid faults via a single-converter-based novel control strategy," IEEE Trans. Power Deliv. 35 (2020) 1330 (DOI: 10.1109/TPWRD.2019.2940771).

[13] P.K. Jain, et al.: "Analysis and design considerations of a load and line independent zero voltage switching full bridge DC/DC converter topology,” IEEE Trans. Power Electron. 17 (2002) 649 (DOI: 10.1109/TPEL.2002.802181).

[14] S.-Y. Lin and C.-L. Chen: "Analysis and design for RCD clamped snubber used in output rectifier of phase-shift full-bridge ZVS converters," IEEE Trans. Ind. Electron. 45 (1998) 358 (DOI: 10.1109/41.681236).

[15] G. Zhang, et al.: "Enhanced one-cycle control for multicell power converters," IEEE Trans. Power Electron. 35 (2020) 8846 (DOI: 10.1109/TPEL.2020.2967630).

[16] Y.-L. Juan, et al.: "Interleaved PFC balance charger with passive lossless snubber for series-connected batteries," IEICE Electron. Express 16 (2019) 20190556 (DOI: 10.1587/elex.16.20190556).

[17] J.-G. Cho, et al.: "Zero-voltage and zero-current-switching fullbridge PWM converter using secondary active clamp," IEEE Trans. Power Electron. 13 (1998) 601 (DOI: 10.1109/63.704125).

[18] C.-Y. Lim, et al.: "Phase-shifted full-bridge DC-DC converter with high efficiency and high power density using center-tapped clamp circuit for battery charging in electric vehicles," IEEE Trans. Power Electron. 34 (2019) 10945 (DOI: 10.1109/TPEL.2019.2899960).

[19] X. Wu, et al.: "Soft switches full bridge DC-DC converter with reduced circulating loss and filter requirement," IEEE Trans. Power Electron. 22 (2007) 1949 (DOI: 10.1109/TPEL.2007.904211).

[20] W. Chen, et al.: "Zero-voltage-switching PWM full-bridge converter employing auxiliary transformer to reset the clamping diode current," IEEE Trans. Power Electron. 25 (2010) 1149 (DOI: 10.1109/ TPEL.2009.2038698).

[21] X. Ruan and F. Liu: "An improved ZVS PWM full-bridge converter with clamping diodes," Proc. IEEE Power Electron. Spec. Conf. (2004) 1476 (DOI: 10.1109/PESC.2004.1355642).

[22] X. Ruan and Y. Yan: "A novel zero-voltage and zero-current- 
switching PWM full-bridge converter using two diodes in series with the lagging leg," IEEE Trans. Ind. Electron. 48 (2001) 777 (DOI: 10.1109/41.937410).

[23] T.T. Song and N. Huang: "A novel zero-voltage and zero-currentswitching full-bridge PWM converter," IEEE Trans. Power Electron. 20 (2005) 286 (DOI: 10.1109/TPEL.2004.843016).

[24] G. Zhang, et al.: "Advanced four-mode-modulation-based four-switch non-inverting buck-boost converter with extra operation zone," IET Power Electron. 13 (2020) 2049 (DOI: 10.1049/iet-pel.2019.1540).

[25] S.-J. Jeon and G.-H. Cho: "A zero-voltage and zero-current switching full-bridge DC-DC converter with transformer isolation," IEEE Trans. Power Electron. 16 (2001) 573 (DOI: 10.1109/63.949490).

[26] L. Zhao, et al.: "A dual half-bridge converter with current doubler rectifier,” IEEE Trans. Ind. Electron. 67 (2020) 6398 (DOI: 10.1109/ TIE.2019.2935986).

[27] L. Zhao, et al.: "Zero-voltage and zero-current switching dualtransformer-based full-bridge converter with current doubler rectifier," IEEE Trans. Power Electron. 35 (2020) 12949 (DOI: 10.1109/ TPEL.2020.2997017).

[28] I.-O. Lee and G.-W. Moon: "Analysis and design of phase-shifted dual H-bridge converter with a wide ZVS range and reduced output filter," IEEE Trans. Ind. Electron. 60 (2013) 4415 (DOI: 10.1109/ TIE.2012.2213564).

[29] I.-O. Lee and G.-W. Moon: "Soft-switching DC/DC converter with a full ZVS range and reduced output filter for high-voltage applications," IEEE Trans. Power Electron. 28 (2013) 112 (DOI: 10.1109/ TPEL.2012.2199520).

[30] L. Zhao, et al.: "A dual half-bridge converter with hybrid rectifier for DC power supply in railways systems," IEEE Trans. Power Electron. 35 (2020) 4579 (DOI: 10.1109/TPEL.2019.2946046).

[31] D.-Y. Kim, et al.: "Variable delay time method in the phase-shifted full-bridge converter for reduced power consumption under light load conditions," IEEE Trans. Power Electron. 28 (2013) 5120 (DOI: 10.1109/TPEL.2013.2237926). 